\title{
A Precariedade do Transporte Rodoviário Brasileiro para o Escoamento da Produção de Soja do Centro-Oeste: situação e perspectivas
}

\author{
Vivian Helena Capacle Correa ${ }^{1}$ \\ Pedro Ramos ${ }^{2}$
}

Resumo: O Centro-Oeste do Brasil se destaca como um pólo produtor de soja. Pela crise fiscal do Estado, a partir dos anos 80 , a malha rodoviária brasileira perde investimentos públicos para sua ampliação, conservação e restauração, refletindo na competitividade internacional da oleaginosa dos cerrados. Isso porque $o$ principal modal utilizado para o escoamento da produção do grão aos portos das regióes Sul e Sudeste é o rodoviário, com destaque para as rodovias BR 163 e 364. Por conta da inadequação desse modal às características do produto e às longas distâncias percorridas, aliada ao estado precário de conservação da malha rodoviária do País, $25 \%$ da receita de vendas da produção de soja está comprometida com os custos internos de transportes. Neste trabalho, apontam-se perspectivas e possíveis soluções à reversão desse cenário, via concessões rodoviárias e Parcerias Público-Privadas (PPP). Analisa-se o uso de diferentes modais para o escoamento da soja do Centro-Oeste, e conclui-se que os hidroviários e ferroviários são os mais eficientes, em razão da eficiência energética e da maior produtividade à movimentação de cargas de densidade mais elevadas por distâncias maiores - $\mathrm{o}$ que conferiria custos menores de circulação.

Palavras-chave: infraestrutura de transportes, rodovias, soja, competitividade.

Abstract: The Center-Western of Brazil is known to be a soy production center. At the beginning of the 80's, because of a governmental fiscal crises, the Brazilian road infrastructure and conservation lost its investment, which reflected on the soy

1 E-mail: vivian@eco.unicamp.br

2 E-mail: peramos@eco.unicamp.br 
international competition. The main transportation used to deliver this product to the ports at the South and South-Eastern regions is the roads, highlighting the BR 163 and 364 road's. Due to the inadequacy of the roads to the characteristics of this product, the long distances that have to be filled and also the bad conservation state of the Brazilian roads, $25 \%$ of this products sales are already accounted for internal transportation costs. There are a few alternatives appointed, such as road concessions and Public-Private Partnership (PPP). This paper analyzes the use of more efficient transportation modals. The conclusion is that the use of river and rail-road transportation modals are more efficient to transport the soy from the Center-Western region of the country, because of higher energetic and transportation efficiency due to the movement of higher density cargo at higher distances - what would reduce circulation costs.

Key-words: transportation infrastructure, roads, soybean, competition.

Classificação JEL: Q18, Q19.

\section{Introdução}

É reconhecido que o agronegócio brasileiro é uma das mais importantes fontes geradoras de riquezas para o País, sendo responsável por cerca de $30 \%$ do Produto Interno Bruto (PIB), por 35\% da mão de obra empregada e por $40 \%$ das exportações nacionais.

Dentro desse conjunto, destaca-se a cultura da soja, cuja produção consolidouse na região Centro-Oeste do País, tendo apresentado, nos últimos anos, uma significativa expansão da área ocupada, com ganhos evidentes de rendimentos.

Como resultado das elevadas inversões públicas na infraestrutura de transportes rodoviários, o Centro-Oeste foi contemplado com importantes rodovias federais. É o caso das rodovias BR 163 e BR 364, que hoje se constituem em rotas de escoamento da produção de soja com destino aos portos de exportação das regiões Sul e Sudeste.

Contudo, a peculiaridade da economia brasileira a partir do início da década de 80 , com a deterioração das contas públicas, culminou em um efetivo abandono de políticas setoriais para a área de infraestrutura de transportes. $\mathrm{O}$ escoamento da soja do Centro-Oeste, por concentrar-se no modal rodoviário e este estar em estado precário de conservação, teve significativas perdas. $\mathrm{O}$ custo logístico do País aumentou expressivamente, superando, em média, em 83\% o dos Estados Unidos e em 94\% o da Argentina, principais concorrentes brasileiros no setor de soja, conforme apontam Jank et al. (2004/05).

Este é o tema em que o presente trabalho está inserido. Ele trata o problema do escoamento da produção de soja da região Centro-Oeste do País para os portos das regiões Sul e Sudeste, vias as rodovias BR 163 e BR 364. O principal modal utilizado 
neste caso é o rodoviário, cujas vias estão em estado precário de conservação, em decorrência da escassez de investimentos públicos em conservação, restauração e pavimentação. Enquanto a produção de soja se expandia e se consolidava na região, não se observava demanda por uma infraestrutura adequada e eficiente para o escoamento da produção, ou seja, não houve aparente preocupação com a criação de alternativas para o transporte.

Além de identificar tal ineficiência, este trabalho busca apontar perspectivas e possíveis soluções, por meio de concessões rodoviárias e de Parcerias PúblicoPrivadas (PPP), visando reverter o estado precário de conservação das rodovias que abastecem o Centro-Oeste e que se constituem em rotas de escoamento da produção de soja, a exemplo das rodovias BR 163 e BR 364. Identifica-se e se analisa o uso de modais mais eficientes para esse transporte e o desenvolvimento de rotas alternativas, que possam gerar contribuições à economia brasileira.

Para oalcance dos objetivos deste trabalho, realizou-se uma revisão bibliográfica e utilizaram-se dados secundários sobre temas relacionados ao problema do escoamento da produção de soja do Centro-Oeste brasileiro. O estudo foca o modal rodoviário, em detrimento de outros modais também presentes na região, mas utilizados em menor escala para o transporte do grão. Também concentra sua análise nas BR 163 e BR 364, por serem as principais rodovias para o escoamento da produção. Utilizou-se, ainda, de dados secundários sobre os custos do escoamento da soja pelo modal rodoviário, que apontaram vantagem econômica para a região Norte do País.

Entre as fontes deste trabalho estão pesquisas desenvolvidas pelo Grupo de Pesquisa e Extensão em Logística Agroindustrial, da Escola Superior de Agricultura Luiz de Queiroz da Universidade de São Paulo (Esalq-LOG), pelo Centro de Estudos em Logísticas (CEL), do Instituto Coppead de Administração da Universidade Federal do Rio de Janeiro (UFRJ), pelo Instituto Brasileiro de Economia, pela Companhia Nacional de Abastecimento (Conab), etc.

Para fundamentar as conclusões, foram realizadas visitas técnicas a instituições e entidades de classe que atuam no segmento da logística brasileira - Associação Brasileira das Concessionárias Rodoviárias (ABCR), Centro de Excelência em Engenharia de Transportes (Centran), Conab e Ministério da Fazenda -, bem como aplicados questionários a profissionais pertencentes a esses órgãos.

\section{A logística do escoamento da soja e o caso da região Centro-Oeste}

Embora seja uma importante região produtora e exportadora de soja, o CentroOeste brasileiro não conta com infraestrutura adequada para o escoamento da oleaginosa, concentrado no modal rodoviário. As condições precárias de conservação das rodovias sob a administração do Estado refletem em perdas na produção. 
Por ser um produto de baixo valor agregado ${ }^{3}$ e transacionado em elevados volumes, a soja em grão necessita de um modal de transporte de grande capacidade e baixo custo unitário, mesmo que não sejam considerados outros atributos, como a frequência e o prazo de entrega da produção (FLEURY, 2005).

$\mathrm{O}$ modal rodoviário vem a ser mais adequado para o transporte de cargas em distâncias consideradas curtas, ou seja, para trajetos de até 300 quilômetros. Atuaria assim, nas chamadas pontas - do local de origem (nesse caso fazendas produtoras) até os armazéns ou terminais ferroviários ou hidroviários, os quais, então, ficariam responsáveis pelo transporte a longas distâncias, dadas a maior capacidade de carga e a possibilidade de reduzir custos e perdas (HIJJAR, 2004).

A ineficiência no transporte da soja produzida no Centro-Oeste do Brasil se dá justamente pela escolha do modal rodoviário como meio unimodal interligando a origem e o destino das cargas -, em vez de utilizá-lo como conexão multimodal (rodo-hidroviário ou rodo-ferroviário).

Apesar da existência de outros meios para o transporte da soja produzida no Centro-Oeste, a exemplo das hidrovias do Madeira e do Tietê - únicas vias hidroviárias utilizadas em larga escala para o escoamento de grãos do País -, o modal rodoviário predomina. Enquanto esse sistema participa com $67 \%$ dos modais, o hidroviário responde por apenas $5 \%$ e o ferroviário, por $28 \%$ (TAVARES, 2004). Assim, os transportes hidroviários e ferroviários são insuficientes para suprir a demanda por estrutura logística, que aumenta principalmente no período de safra. ${ }^{4}$

Em termos de eficiência, os dois últimos modais citados (hidroviário e ferroviário) são mais adequados para o transporte de cargas de baixo valor agregado a longas distâncias - caso da soja -, devido à capacidade de deslocar grandes volumes consumindo pouco combustível.

Conforme Coeli (2004), no modal ferroviário consome-se quatro vezes menos combustível que no rodoviário, tornando o primeiro mais vantajoso para o escoamento de cargas a longas distâncias. Assim, se operado eficientemente, o transporte ferroviário de elevada capacidade de carga e caracterizado por baixos custos variáveis, poderia apresentar menores custos de transporte (CAIXETA et al., 1998). Da mesma forma, quanto ao modal hidroviário, Caixeta et al. (1998) apontam que um conjunto de barcaças consome menos da metade do

3 O valor agregado para a produção de soja em 2003 foi de US\$ 216 por tonelada, enquanto o valor agregado da produção industrial teve média de US\$ 6.610 por tonelada (Fleury, 2005).

4 É também notória a ineficiência na estrutura portuária brasileira (calado, dragagem, acessos tanto por ferrovia quanto por rodovia) para o escoamento da produção de grãos, acarretando em maiores custos de exportação. São utilizados cerca de 1.000 navios com capacidade para 50.000 toneladas. Esses navios chegam a esperar, em média, 22 dias para serem carregados, sendo o custo de demurrage (multa decorrente dos atrasos portuários no embarque ou desembarque de mercadorias) de US\$ 50 mil, por dia, em média - 2004 (HIJJAR, 2004). 
combustível gasto por um comboio ferroviário, para mesmos volume de carga e distância.

Anciães et al. (1980) apresentam uma comparação entre as eficiências de cada modal de transporte, do ponto de vista energético, expressas em megajoules por tonelada-quilômetro (MJ/ton-km). Os resultados evidenciam que o modal aéreo é o que mais consome energia, seguido pelas modalidades rodovia, ferrovia, hidrovia e dutovia.

Tabela 1. Eficiência energética entre as modalidades de transporte de carga.

\begin{tabular}{lcc}
\hline \multicolumn{1}{c}{ Modalidade } & Ton-K $\mathbf{~} / \mathbf{1}^{*}$ & MJ/ton-km \\
\hline Rodovia & 25 & 3,53 \\
Ferrovia & 88 & 1,02 \\
Hidrovia & 98 & 0,93 \\
Aerovia & 2 & 40,70 \\
Dutovia & 120 & 0,74 \\
\hline
\end{tabular}

* Equivalência comparativa para quando as cargas têm a mesma densidade.

Fonte: Modificado a partir de Anciães et al. (1980).

Para Afonso (2006), o uso do modal hidroviário no transporte de cargas representaria uma redução nos custos de $44 \%$ em relação ao ferroviário e de $84 \%$ frente ao rodoviário. A Tabela 2 reproduzida pelo autor compara algumas variáveis entre os modais, que evidenciam maior vantagem à hidrovia para o transporte de cargas a longa distância. Torres (2006) calcula que a tonelada transportada por $1.000 \mathrm{~km}$ custaria $\mathrm{R} \$ 100,00$ pela rodovia, $\mathrm{R} \$ 65,00$ pela ferrovia, enquanto pela hidrovia o custo seria bem inferior, de $\mathrm{R} \$ 40,00$.

Tabela 2. Vantagem do modal hidroviário sobre os demais modais.

\begin{tabular}{|c|c|c|c|}
\hline Atributos & Barco & Trem & Caminhão \\
\hline Peso morto por tonelada transportada & $350 \mathrm{~kg}$ & $800 \mathrm{~kg}$ & $700 \mathrm{~kg}$ \\
\hline Força de tração - 1 CV arrasta sobre & $4.000 \mathrm{~kg}$ & $500 \mathrm{~kg}$ & $150 \mathrm{~kg}$ \\
\hline $\begin{array}{l}\text { Energia: } 1 \mathrm{~kg} \text { de carvão mineral leva } \\
1 \text { tonelada }\end{array}$ & $40 \mathrm{~km}$ & $20 \mathrm{~km}$ & $6,5 \mathrm{~kg}$ \\
\hline $\begin{array}{l}\text { Investimentos para transportar mil } \\
\text { toneladas, em milhões de US\$ }\end{array}$ & 0,46 & 1,55 & 1,86 \\
\hline $\begin{array}{l}\text { Quantidade de equipamento para } \\
\text { transportar mil toneladas }\end{array}$ & $\begin{array}{c}1 \text { empurrador } \\
\text { e } 1 \text { balsa }\end{array}$ & $\begin{array}{l}1 \text { locomotiva } \\
\text { e } 50 \text { vagões }\end{array}$ & $\begin{array}{c}50 \text { cavalos mecânicos e } \\
50 \text { reboques }\end{array}$ \\
\hline $\begin{array}{l}\text { Distância }(\mathrm{km}) \text { percorrida com } 1 \text { litro } \\
\text { de combustível e carga de } 1 \text { tonelada }\end{array}$ & $219 \mathrm{~km}$ & $86 \mathrm{~km}$ & $25 \mathrm{~km}$ \\
\hline Vida útil em anos de uso & 50 & 30 & 10 \\
\hline $\begin{array}{l}\text { Custo médio }(\mathrm{R} \$ / \mathrm{km}) \text { tonelada por } \\
\mathrm{km} \text { transportado }\end{array}$ & 0,009 & 0,016 & 0,056 \\
\hline
\end{tabular}

Fonte: Afonso (2006). 
452 - A Precariedade do Transporte Rodoviário Brasileiro para o Escoamento da Produção de Soja do Centro-Oeste: situação e perspectivas

Embora apresente custos baixos, o modal hidroviário nem sempre atende a todos os quesitos para a movimentação de uma produção (características do produto, locais de origem e destino, entre outros). Por ser mais flexível, ao acessar, por exemplo, áreas não alcançadas pela ferrovia ou hidrovia, o transporte rodoviário, muitas vezes, dependendo do produto e da situação, acaba sendo o modal preferido para o deslocamento. Outro limitante é que, no Brasil, os transportes não são integrados, ao contrário da situação desejada, que consideraria, ainda, os custos energéticos. ${ }^{5}$

Para o transporte de commodities, a intermodalidade (rodovia/hidrovia/ ferrovia) é muito mais vantajosa se comparada ao uso isolado da rodovia, com os custos sendo entre $15 \%$ e $20 \%$ menores (TORRES, 2006). No entanto, a baixa densidade de hidrovias e ferrovias no Brasil (o equivalente a $5,6 \mathrm{~km} / 1.000 \mathrm{~km}^{2}$ e a $3,4 \mathrm{~km} / 1.000 \mathrm{~km}^{2}$, respectivamente, contra $17,3 \mathrm{~km} / 1.000 \mathrm{~km}^{2}$ no modal rodoviário) limita o uso da intermodalidade (CNT, 2002).

Mas infraestrutura ferroviária e hidroviária do País é insuficiente para realizar o transporte de grãos. Isso faz com que seja necessária a utilização do modal rodoviário para o transporte de grande parte da produção de soja brasileira, mesmo quando se trata de longas distâncias. O problema dessa predominância também se dá pelo baixo aproveitamento do transporte, pois carrega menos soja do que uma composição ferroviária e/ou hidroviária (ROESSING et al., 2007, p. 6).

Além disso, os modais tanto ferroviário como hidroviário não fazem a conexão direta entre os pares de origem e destino. No caso da multimodalidade (rodovia/hidrovia/ferrovia), seria função da rodovia o transporte da mercadoria do seu local de origem até o transbordo para o modal mais eficiente, o qual faria a movimentação de cargas de baixo valor agregado a distâncias maiores, como é o caso da soja.

Apesar da existência de rotas de escoamento de soja da região Centro-Oeste por hidrovias e ferrovias, as rodovias ainda são as mais demandadas, por conta do menor custo generalizado. Ademais, o unimodal rodoviário é o mais viável, dada a flexibilidade em atuar porta a porta, além de não exigir transbordos, não impor perdas de tempos, entre outros aspectos que refletem no custo maior de circulação. Por outro lado, como as vias hidroviárias e ferroviárias não atingem os centros produtores, as cargas percorrem trechos longos e mal conservados de rodovias até o transbordo a outro modal.

Portanto, é pelo menor custo generalizado que o escoamento dessa produção se concentra no modal rodoviário. Mas são várias as razões que fazem com que o modal rodoviário não seja adequado ao escoamento da produção de soja do Centro-

5 Do ponto de vista energético, a melhor alternativa de transporte entre dois pontos seria aquela em que o consumo de energia fosse mínimo, expresso, por exemplo, em megajoules por tonelada-quilômetro. 
Oeste para os portos de exportação nas regiões Sul e Sudeste, quais sejam: a longa distância a ser percorrida aliada a variáveis inerentes a esse modal, como a pequena capacidade de cargas; o custo médio superior (tonelada/km) e, de maior relevância, o maior consumo de energia. Assim sendo, o país tem perdas na competitividade da produção de soja, pelo fato do escoamento dessa produção se concentrar no modal rodoviário, o qual é inadequado para o transporte de cargas volumosas e de baixo valor agregado, além de encontrar-se com as vias em estado precário de conservação, a exemplo das vias que abastecem a Região Centro-Oeste do país. Os modais hidroviários e ferroviários, seriam os mais indicados para o escoamento da produção de soja do Centro-Oeste, dado que o modal rodoviário impõe maiores preços de fretes, em razão da maior distância desta região aos portos de exportação.

...um caminhão carrega cerca de 150 vezes menos soja do que uma composição ferroviária e cerca de 600 vezes menos do que um comboio de barcaças numa hidrovia como a do Rio Madeira. E além dessa menor produtividade para longas distâncias e grandes volumes, o transporte rodoviário é mais poluente, gasta mais combustível e registra índices de acidentes muito mais elevados (HIJJAR, 2004, p. 5).

Portanto, são dois tipos de custos logísticos relacionados ao modal rodoviário que inferem na competitividade internacional da soja brasileira em grão. $\mathrm{O}$ primeiro está atrelado à inadequação desse modal às características do produto e às distâncias percorridas e, o segundo, à precária malha rodoviária do País, em razão da escassez de recursos que se alastrou sobre as políticas públicas de infraestrutura, a partir dos anos 80 .

Ao analisar a matriz de transportes de cargas no Brasil no contexto históricopolítico, tem-se que a concentração logística no modal rodoviário tem sua raiz no período de desenvolvimento da indústria automobilística e dos baixos preços do petróleo, principalmente após a segunda metade da década de 50, quando, então, se observou a expansão dessa modalidade.

Por volta de 1940-1950, portanto, se imperou uma cultura 'rodoviarista', já que, conforme aponta Natal (1991), a concentração econômica industrial no estado de São Paulo, ou, no Centro-Sul do País inviabilizava a integração regional via férrea. Além disso, o rodoviarismo suscitava um forte apelo econômico e moderno, contribuindo para o processo de formação de mercado e de integração nacional. O modal rodoviário automobilístico, portanto, era visto como uma revolução no padrão nacional de transportes, transpondo os ares da modernidade do século $\mathrm{XX}$ ao Brasil, enquanto o modal ferroviário se caracterizava como 'coisa do passado'.

A ênfase no transporte rodoviário se deu não apenas pelo fato de ser o mais adequado ao período pelo qual passava a economia brasileira - de concentração econômica e industrial na região Centro-Sul -, de modo a permitir interligações diretas entre a origem e os centros de distribuição das mercadorias. Do ponto de vista das inversões de capital, ou seja, dos custos fixos iniciais, o modal rodoviário 
é mais barato que o ferroviário, uma vez que os investimentos em rodovias podem ser espaçados no tempo, abrindo-se, primeiramente, o caminho, em piso de terra, para posterior asfaltamento.

Conforme apontam Baumel e Gervais, (1999) apud Afonso, (2006), os investimentos iniciais para se implantar rodovia e hidrovia são, respectivamente, $25 \%$ e $6 \%$ menores que o montante necessário para a ferrovia. No entanto, se considerada a geografia da região, englobando suas especificidades de relevo, esses valores podem se alterar, de modo a tornar o investimento inicial de uma ferrovia muito inferior ao de uma rodovia.

Pode-se concluir que as ferrovias não se revitalizaram no Brasil, a partir do momento de implantação e ênfase do modal rodoviário, em razão da maior demanda por recursos para investimentos (já escassos) e do apelo econômico e moderno da indústria automobilística. Portanto, a consolidação do padrão rodoviário de transportes no País apresenta não somente um viés econômico, mas, principalmente, cultural.

Ao analisar o escoamento da soja focado no modal rodoviário da região CentroOeste, conclui-se que, pelo abandono do Estado das políticas desenvolvimentistas no País, quando de sua crise fiscal, não foi dada a devida atenção à infraestrutura de transportes, essencial para o crescimento e dinamismo da produtividade de um setor.

No intuito de calcular as ineficiências do modal rodoviário para longas distâncias e alta densidade de cargas, Caixeta; Bartholomeu (2002) consideraram o consumo de diesel para transportar, via rodovia, uma tonelada de carga por $100 \mathrm{~km}$. Os autores observaram que, os trajetos em piores condições de conservação demandam mais combustível, sendo 63\% menos eficientes energicamente que aqueles realizados em vias conservadas.

De acordo com Bartholomeu (2006) ${ }^{6}$, os resultados da quantificação dos impactos econômicos e ambientais decorrentes do estado de conservação das estradas brasileiras mostram que as rotas consideradas "Melhores" apresentam economia de 5,07\% de combustível. Ao considerar um preço médio de $\mathrm{R} \$ 1$,915/ litro de diesel (ao preço de maio de 2006) os benefícios auferidos pelo uso da "Melhor" rota em relação a "Pior" rota é de 2,51 1/100 km, sendo o valor do beneficio $\mathrm{R} \$ / 100 \mathrm{~km}$ de 4,81 .

Ao realizar um cálculo comparativo, a partir de carretas convencionais, observa-se que para o transporte de 1.000 toneladas de soja, são necessárias 50 carretas. Em 2005, da exportação de 9.086 milhões de toneladas de soja pelo estado de Mato Grosso, 60\% destinaram-se aos portos das regiões Sul e Sudeste do País, num total de 5.451 milhões de toneladas. ${ }^{7}$ Para se chegar aos portos de Santos e Paranaguá, por exemplo, a distância média é de 2.000 quilômetros, e,

6 Tese de Doutorado (Economia Aplicada) defendida na Escola Superior de Agricultura Luiz de Queiroz (Esalq), da Universidade de São Paulo, sob a orientação do Professor José Vicente Caixeta Filho (2006).

7 IBGE. Anuário Estatístico do Brasil, 2005; Famato, 2007. 
se toda essa extensão estivesse em bom estado de conservação, o benefício seria de cerca de $\mathrm{R} \$ 5 \mathrm{mil}^{8}$ por tonelada, o que representaria um benefício de $\mathrm{R} \$ 27$ milhões ao exportar a produção de soja daquele estado por esses portos.

Portanto, se o escoamento da produção de soja do Centro-Oeste ocorresse em vias rodoviárias que estivessem em bons estados de conservação, haveria significativas reduções nos custos de transporte, principalmente nas vias da região, cujo estado precário de conservação se infere em perdas à sojicultura. Ademais, há que se apontar que o uso dos modais hidroviários e ferroviário conferiria menores perdas à essa produção.

Para Roessing et al. (2007), a questão da otimização logística da soja brasileira está relacionada à necessidade de incrementar a competitividade da produção nacional frente à concorrência externa, pois, dentre os segmentos que inferem na eficiência de diversos setores de uma economia, é o de transportes o mais significativo. Assim, o produtor brasileiro de soja tem uma perda média de $25 \%$ em suas receitas com custos de transporte, enquanto para um produtor norte-americano essa despesa média é inferior a $10 \%$ da receita obtida. Isso porque no Brasil, o transporte rodoviário responde por $67 \%$ do escoamento da produção de soja a distâncias de 900 a $1.000 \mathrm{~km}$ (destaca-se, ainda, que a maior parte das vias rodoviárias está em estado precário de conservação) e os modais hidroviários e ferroviários, por 5\% e 28\%, nesta ordem. Nos Estados Unidos, mesmo apresentando distâncias médias de trajetos parecidas com as do Brasil, 61\% desse transporte são realizados por hidrovias, 23\% por ferrovias e, apenas $16 \%$, por rodovias. No caso argentino, apesar de $82 \%$ do escoamento da produção de soja ser realizada pelo modal rodoviário, as distâncias percorridas são em média de 250 a 300 km (ROESSING e LAZZAROTTO, 2005).

A Tabela 3 apresenta um comparativo das cadeias sojícolas do Brasil, Argentina e Estados Unidos, evidenciando os maiores custos logísticos para o caso brasileiro.

Tabela 3. Comparativo de sustentabilidade das cadeias, em US\$/t

\begin{tabular}{lcccc}
\hline & $\begin{array}{c}\text { EUA } \\
\text { (Illinois) }\end{array}$ & $\begin{array}{c}\text { Mato Grosso } \\
\text { (Sorriso) }\end{array}$ & $\begin{array}{c}\text { Paraná } \\
\text { (Campo Mourão) }\end{array}$ & $\begin{array}{c}\text { Argentina } \\
\text { (Pampa) }\end{array}$ \\
\hline Custo de Produção & 203.5 & 174.0 & 145.0 & 158.8 \\
Frete ao Porto & 26.0 & 47.0 & 17.0 & 13.4 \\
Despesas Porto & 3.0 & 5.3 & 5.3 & 3.0 \\
Transporte Marítimo & 21.4 & 23.4 & 23.4 & 25.4 \\
Prêmio & $(13.0)$ & 80.0 & 80.0 & 58.0 \\
Custo Total & 240.9 & 329.7 & 270.87 & 258.6 \\
\hline
\end{tabular}

* O prêmio está relacionado às operações portuárias inerentes à recepção da carga, estocagem, atracamento de navios, etc. Valor: US\$ $1=\mathrm{R} \$ 3,00$.

Fonte: Tavares (2004).

8 O benefício da melhor rota em relação a pior é de $\mathrm{R} \$ 4,81 / 100 \mathrm{~km} .2 .000 \mathrm{mil} \mathrm{km} /$ $100 \mathrm{~km}=20 \times 4,81=\mathrm{R} \$ 96,20.50$ carretas $\times \mathrm{R} \$ 96,0=\mathrm{R} \$ 4.810,00$ por tonelada. Se o cálculo fosse realizado para caminhões bi-trem, o benefício seria de R 13 milhões, já que para se transportar 1.000 toneladas de soja são necessários apenas 25 caminhões. 
A soja da região Centro-Oeste tem maior vantagem competitiva, mas, como aponta Tavares (2004), pela maior distância de Mato Grosso (estado de maior relevância nacional na produção do grão) em relação aos portos de destino, o uso do modal rodoviário como meio unimodal aliado ao estado precário das rodovias é o que prejudica a rentabilidade dos produtores. Os custos logísticos do País são significativamente mais elevados que os observados nos Estados Unidos e Argentina.

Supõe-se, portanto, o uso dos modais ferroviário e hidroviário no Brasil para o escoamento dessa produção. Porém, o transporte ferroviário brasileiro apresenta uma baixa oferta de infraestrutura, além de problemas de viabilidade econômica, enquanto para o hidroviário, são as inviabilidades de navegação ainda existentes a alguns trechos que limitam a sua efetivação.

Embora se saiba que o modal rodoviário é insuficiente e inadequado para movimentar a produção de soja da região Centro-Oeste até os portos de exportação, é ele que impera na matriz brasileira de transportes de cargas, em razão da insuficiência dos outros modais.

Há que se considerar, ainda, a uma expansão da cultura de soja para outras regiões nacionais, como o nordeste do Maranhão, nordeste e sudeste do Pará, Tocantins e o centro-sul do Piaú, sem que haja crescimento na capacidade dos portos de exportação e na condição logística do País, concentrada no modal rodoviário (Conab, 2007).

Reconhece-se, portanto, que o Centro-Oeste, conforme aponta o Ministério da Integração Nacional (2006), carece de uma infraestrutura de transportes eficiente para a sua produção agropecuária, devido às dificuldades financeiras do setor público e às restrições ambientais que empatam a condução de certos investimentos logísticos, por exemplo. Em muitos casos, os atrasos na implantação das obras decorrem das exigências e impedimentos dos órgãos ambientais, das pressões dos movimentos ambientalistas ou das decisões do Ministério Público, a exemplo do fechamento do terminal graneleiro de Santarém (PA) da trading multinacional de grãos Cargill' .

Assim, o aumento da competitividade da estrutura produtiva do País e, portanto, da produção de soja da região Centro-Oeste depende de investimentos na expansão da infraestrutura de transportes, tanto no desenvolvimento de

9 O terminal graneleiro da empresa teve suas atividades paralisadas em março de 2007 por fiscais do Instituto Brasileiro do Meio Ambiente (Ibama), referindo-se a uma ação movida pelo Ministério Público Federal em 2000, sob a alegação de que o porto teria incentivado o desmatamento de áreas da floresta amazônica para o cultivo de soja. Em 2006, cerca de 1 milhão de toneladas de soja foram transportadas por esse porto, sendo que 95\% dos grãos eram provenientes do estado de Mato Grosso. O fechamento do porto faz com que o escoamento da produção da região CentroOeste ocorra pelos portos de Santos e Paranaguá, cujas capacidades estão esgotadas (PEREIRA e MENDES, 2007). 
modais alternativos (ferroviário e hidroviário) como na revitalização da malha rodoviária.

\section{A problemática das rodovias BR 163 e BR 364, na região Centro-Oeste}

A BR 163 e a BR 364 são as principais rodovias para se escoar a produção de soja do Centro-Oeste brasileiro para os portos de exportação das regiões Sul e Sudeste, responsáveis por cerca de $80 \%$ de todo o volume embarcado do complexo soja do País (ROESSING e LAZZAROTTO, 2005). A rodovia BR 163 interliga as áreas produtoras do Centro-Oeste ao porto de Paranaguá (PR), enquanto a rodovia BR 364 liga os estados de Mato Grosso e Rondônia ao porto de Santos (TIMOSSI, 2003).

No entanto, essas rodovias estão com suas vias em estado precário de conservação em razão da escassez de investimentos, o que tem refletido em perdas à competitiva produção sojícola. $\mathrm{O}$ reconhecimento da fragilidade financeira do Estado em realizar investimentos para a revitalização dessas rodovias sugere que a concessão à iniciativa privada venha a ser uma solução eficaz para combater esse gargalo logístico.

Ao mesmo tempo, essas rodovias não apresentam um volume de tráfego suficiente para justificar investimentos privados - do ponto de vista da rentabilidade privada. Estudos indicam que, por alguns trechos rodoviários da região Centro-Oeste, trafegam, em média, cerca de 100 veículos/dia, o que inviabiliza a cobrança do pedágio aos preços cobrados pelas praças existentes. Caso fossem implantados pedágios nessas vias, tanto por empresas concessionárias quanto por empresas públicas, o preço - ideal para rentabilizar o investimento - seria proibitivo para o usuário (informação verbal). ${ }^{10}$

Carlos Alberto Felizola Freire ${ }^{11}$ aponta que o fluxo de veículos, mesmo sendo o mais importante, não é o único fator a ser considerado para que um trecho rodoviário seja objeto de concessão. O passivo ambiental, a segurança regulatória e as condições econômicas e financeiras atraentes para o investidor estão entre outros fatores a serem levados em conta.

A escassez de investimentos públicos em conservação nas rodovias BR 163 e BR 364 tem deteriorado o pavimento dessas vias, sendo que ainda há trechos não pavimentados. As Figuras 1 e 2 apresentam o traçado dessas rodovias, cujas

10 Engenheiro de Transportes Sr. Saul Germano Rabello Quadros, coordenador do núcleo de transportes do Centran, a partir de conversa técnica realizada em fevereiro de 2007.

11 Secretário Executivo da Associação Brasileira das Concessionárias de Rodovias. Informações obtidas a partir de entrevista técnica enviada via e-mail e respondida em 23/02/2007. 
A Precariedade do Transporte Rodoviário Brasileiro para o Escoamento da Produção de Soja do Centro-Oeste: situação e perspectivas

extensões são de $4.450,9 \mathrm{~km}$ e 4.326,2 km, respectivamente. A Figura 1 destaca dois trechos da rodovia BR 163, no estado do Pará, que se encontram ainda sem pavimentação.

Figura 1. Traçado longitudinal da rodovia BR 163 e fotos de trechos selecionados no estado do Pará.

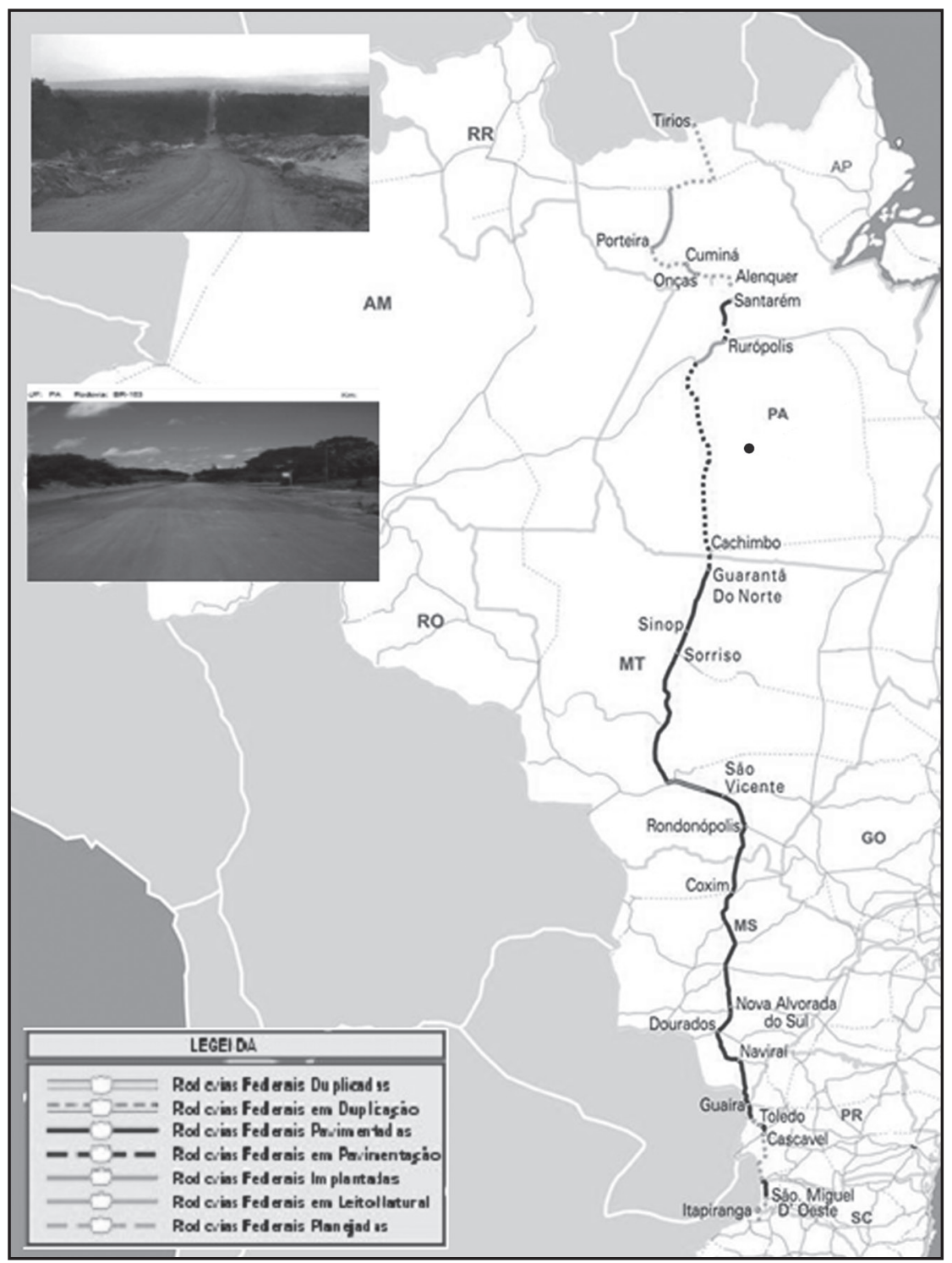

Fonte: Ministério dos Transportes, 2007, e Confederação Nacional dos Transportes (CNT), 2006. 
Figura 2. Traçado diagonal da rodovia BR 364.

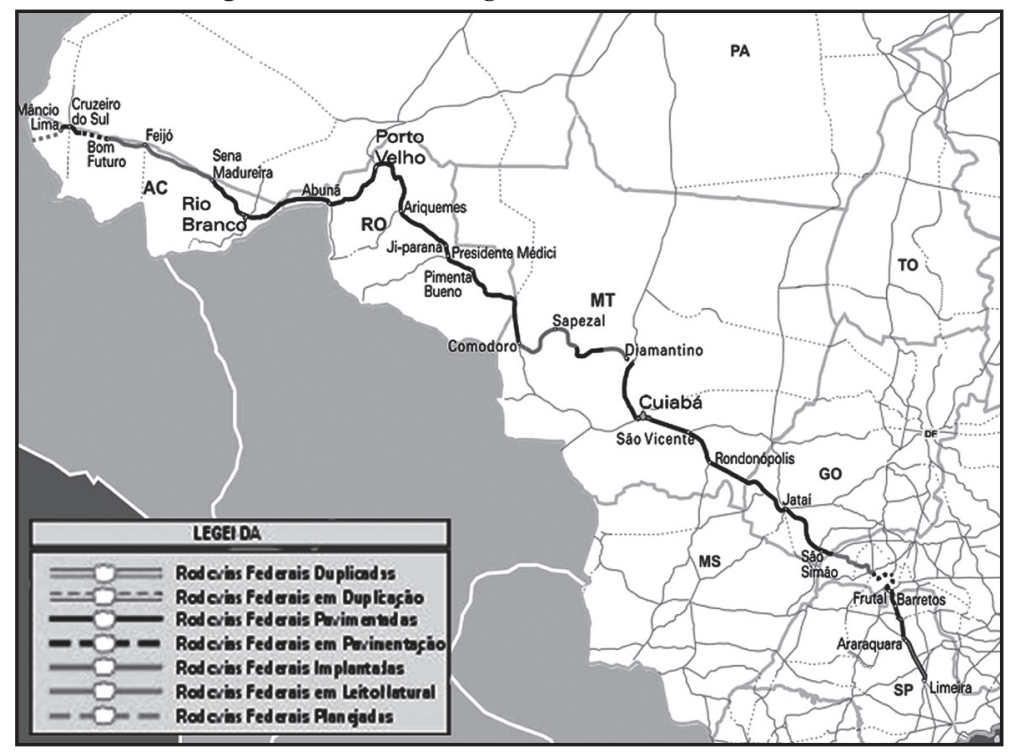

Fonte: Ministério dos Transportes, 2007.

É no estado do Pará que se observa o pior nível de condição dos trechos rodoviários da rodovia BR 163, com parte da extensão - km 99 - ainda em leito natural. Em Mato Grosso e Mato Grosso do Sul, além do asfalto precário, os trechos rodoviários não têm acostamento e apresentam uma sinalização precária, com exceção do km 271 em MS, cuja extensão está duplicada. Nesse sentido, destaca-se que são poucos os trechos duplicados na rodovia BR 163: de sua extensão, $4.450,9$ km, apenas 55 quilômetros são duplicados, sendo, desses, $86 \%$ em MT.

No estado de São Paulo, a BR 364 apresenta a maior porcentagem de trechos pavimentados, o equivalente a $82 \%$ de 231,2 quilômetros de vias asfaltadas de um total de 4.326,2 quilômetros. Por concentrar a maior parte da produção brasileira, o estado recebe significativas parcelas de recursos financeiros federais para a conservação das vias.

Assim, nos anos 70, muitos trechos rodoviários, a exemplo dos das rodovias BR 163 e BR 364, foram planejados e construídos, entre o I Plano Nacional de Desenvolvimento (PND) e II PND. Porém, ainda não foram pavimentados, em decorrência da crise financeira do Estado nos anos 80. Os recursos financeiros públicos às obras de infraestrutura foram direcionados às regiões de maior relevância econômica, como Sul e Sudeste, abandonando o anseio à promoção do crescimento e do desenvolvimento econômico do País por meio da desconcentração econômica regional de períodos anteriores. 
No início da expansão da fronteira agrícola, o Estado esteve sempre presente, incentivando o desenvolvimento da produção no Centro-Oeste. Devido a seu afastamento da esfera econômica, contudo, a política de planejamento regional foi abandonada, sendo que os investimentos para a manutenção das vias rodoviárias da região, nas quais se apoiou o movimento de expansão da fronteira, foram também esquecidos. Se a política pública abandonou os investimentos para a manutenção das vias rodoviárias da região, por onde a produção é escoada, muito menos se atentou para a magnitude econômica agrícola da região e à sua posterior demanda por modais mais eficientes.

Constata-se, portanto, que todo o apoio governamental, centrado nas políticas agrícolas regionais, para a ocupação agrícola no Centro-Oeste e para a elevação da produção de soja, não foi acompanhado de cuidados com a malha rodoviária da região e investimentos em outros modais. Como resultado, a oleaginosa enfrenta perdas de competitividade internacional até hoje.

\section{Perspectivas: as possíveis novas rotas de escoamento da soja e a revitalização da malha rodoviária brasileira}

A expansão da produção de soja para as áreas de fronteira tem demandado meios modais mais eficientes de escoamento, além de alternativas às rotas utilizadas pelas regiões tradicionais. Uma rota alternativa para o escoamento da soja produzida no norte do estado de Mato Grosso e nos estados da região Norte é aquela que se destina aos portos da região Norte do País, como o porto de Itacoatiara (AM). ${ }^{12}$

Por estarem próximos às regiões produtoras de grãos e mais próximos ainda aos mercados consumidores externos, como a Europa, esses portos de exportação proporcionam maiores vantagens competitivas se comparados aos tradicionais. Além da menor distância, esses portos oferecem melhor estrutura, admitindo navios de maior calado que, entre outros fatores, proporcionam menores custos operacionais e, assim, fretes marítimos mais baixos (TIMOSSI, 2003).

Timossi (2003) aponta que, a partir de 2001, houve uma maior participação de portos alternativos no escoamento de soja em grão. $\mathrm{O}$ destaque foi para o porto de Itacoatiara (AM), na hidrovia do rio Madeira, responsável por 7,2\% dos embarques totais, ocupando a quarta posição no ranking dos principais portos. Essa nova rota tem abastecido a produção do norte de Mato Grosso e do estado de Rondônia, oferecendo ganhos médios de até $25 \%$, se comparada à rota com destino ao porto de Paranaguá. Para o Norte do País, representada por

12 Timossi (2003) aponta outra alternativa de escoamento da produção da região sul de Mato Grosso para o porto de Santos via a intermodalidade rodo-ferroviário. Com um custo médio de $12 \%$ inferior ao unimodal rodoviário com destino à Paranaguá, esse meio modal já responde por aproximadamente $40 \%$ do total escoado pelo estado. 
Piauí, Maranhão, Tocantins e Pará, o porto de São Luís (MA) tem sido uma rota alternativa de escoamento, respondendo por $4 \%$ do total exportado do produto.

Assim, as recentes discussões acerca dos embates contra os gargalos logísticos que comprometem o escoamento da produção de soja produzida no CentroOeste do País dizem respeito ao escoamento pelos portos da região Norte.

De acordo com Ibre (2005), a ampliação do escoamento de soja pelo Norte é um imperativo de racionalidade econômica, considerando-se, ainda, que essa produção se expande para os estados dessa região. "É hora, portanto, de se pensar no que deve ser feito para, de forma gradativa, girar o eixo logístico de escoamento da safra rumo ao Norte".

Contudo, a consolidação dessas rotas alternativas, para um dos portos da região Norte, a exemplo do porto de Santarém (PA), depende da pavimentação do trecho da rodovia BR 163, no estado do Pará, até Santarém, ainda em leito natural e já muito descaracterizado. Em épocas de chuva, o tráfego por esse trecho só ocorre com a ajuda de tratores que desatolam os caminhões.

Situado entre a confluência dos rios Tapajós e Amazonas, a cerca de $400 \mathrm{~km}$ do oceano Atlântico, o porto de Santarém (PA) tem capacidade para exportar de 800.000 a 1 milhão de toneladas de grãos. O porto escoa a soja produzida na região e a que vem de comboios de Porto Velho, pela hidrovia do Madeira. ${ }^{13}$ Conforme Ibre (2005), a soja que chega a Porto Velho em caminhões é consolidada em comboios de barcaça, sendo que a distância até Santarém é de $1.500 \mathrm{~km}$, o que torna o percurso até o porto de Santarém mais atraente via modal rodoviário.

Uma análise $^{14}$ feita por Bahia et al. (2007) constatou que o transporte da produção de soja de Mato Grosso até o porto de Santarém (PA) apresentaria um custo logístico $20 \%$ menor que o feito até os portos de Santos e Paranaguá, caso a capacidade desse porto fosse (quase) proporcional à do porto de Paranaguá (5 milhões de toneladas).

A distância da região central de Mato Grosso até o porto de Santarém é de 1.400 km, via a rodovia BR 163, chamada nesse ponto de Cuiabá-Santarém, um trecho considerado pequeno para a região da Amazônia. Porém, o fato é que os cerca de 980 km dessa rodovia no estado do Pará não são asfaltados (IBRE, 2005).

Portanto, para que essa rota de escoamento seja viabilizada é necessária a revitalização/pavimentação da rodovia BR 163 e o pleno funcionamento do

13 O terminal exportador pertence à empresa Cargill, compradora de soja do oeste e noroeste de Mato Grosso, onde está a cidade de Sorriso, um pólo produtor sojícola.

14 Nessa pesquisa, foi utilizada a produção sojícola de cidades importantes de Mato Grosso para o período 2002-2004, numa quantidade produzida de 8.146.767 milhões de toneladas. Utilizou-se o modelo de programação linear (PL) de custo mínimo, na qual a PL é uma técnica de otimização, cujo objetivo foi encontrar o menor custo de transporte das quantidades de soja produzida entre as principais cidades do estado e os Portos de escoamento (Santos, Paranaguá e Santarém). O preço do frete foi em $\mathrm{R} \$ / t$, não havendo influência do estado de conservação viária. 
porto de Santarém, via aumento da capacidade com investimentos em silos, esteiras e berços, por exemplo -, fatores esses poucos considerados quando a discussão é transferir o transporte do grão do Centro-Oeste para os portos da Região Norte.

De acordo com Lopes e Oliveira (2005), o trecho da rodovia BR 163 (CuiabáSantarém) em estado precário de conservação e que demanda recuperação é aquele entre Cuiabá e Guarantã do Norte (MT). O outro trecho consiste na ligação de Guarantã no Norte a Itaituba (PA), com extensão até Rurópolis (PA) de $894 \mathrm{~km}$, além dos $270 \mathrm{~km}$ ligando Rurópolis ao porto de Santarém, onde há um potencial de produção e transporte de cerca de 5 milhões de toneladas por safra, sendo 3,9 milhões de soja e 1,1 milhão de toneladas de milho, arroz e algodão.

Portanto, a pavimentação da rodovia BR 163 entre Cuiabá e Santarém reforçaria a ligação entre o Norte do País e as regiões Centrais e Sudeste, com significativas vantagens ao escoamento da produção nacional (CONAB, 2007). Além de proporcionar menores custos logísticos, o escoamento da produção de soja pelo porto de Santarém proporcionaria uma distribuição das quantidades dessa produção a serem escoadas pelos portos de Santos e Paranaguá, resultando em maiores eficiências no transbordo com reflexos aos custos de demurrage.

No que tange ao escoamento da soja do estado de Mato Grosso, observou-se que a distância para o transporte dessa produção de Lucas do Rio Verde (MT) cidade sob influência do corredor BR 163 - até Santarém é de $1.430 \mathrm{~km}$, enquanto até Paranaguá é de $2.195 \mathrm{~km}$, o que resultaria em economia de $765 \mathrm{~km}$ a favor do direcionamento da produção para o Norte do País.

Pressupondo-se que as condições de trafegabilidade nos trechos entre Lucas do Rio Verde (MT) e Paranaguá fossem idênticas, o escoamento da produção de soja, numa carreta de 40 toneladas, até Paranaguá conferiria um custo rodoviário de $R$ \$ 6.146,00, enquanto para Santarém o custo é de R \$ 2.860. Considerando que a produção agrícola gerada nos municípios da região Centro-Oeste sob a influência da rodovia BR 163 cria um excedente exportável de aproximadamente seis milhões de toneladas, a economia gerada pelo escoamento para o Norte do País seria de $\mathrm{R} \$ 246$ milhões $^{15}$ (CONAB, 2007).

Assim, observam-se vantagens no escoamento da produção de soja do Centro-Oeste para o Norte do País - escoamento este que demanda a pavimentação da rodovia BR 163. As plataformas de embarque na região Norte em operação, atualmente, são aquelas em Itacoatiara (MA) do grupo André Maggi, com capacidade de processamento entre 2,5 e 3 milhões de toneladas por ano, e em Santarém, terminal do grupo Cargill, com capacidade para 800.000 toneladas por ano (SILVA, 2005).

15 Estimativa de cálculo: $\mathrm{R} \$ 6.146,00-2.860,00=\mathrm{R} \$ 3.286,00$ (vantagem em direcionar para os portos da região Norte do País). 6 milhões de toneladas / $40 \mathrm{t}=150.000$ viagens $x$ R \$ 3.286,00/R\$/US\$2,00 = US\$ 246,4 milhões. 
Quanto à revitalização da rodovia BR 163, diante da situação escassa de financiamentos públicos, destaca-se que a pavimentação dessa rodovia, no estado do Pará, bem como a reversão do estado precário dessa e da rodovia BR 364 poderiam ser realizadas pela iniciativa privada por meio de concessão, se as mesmas proporcionassem fluxos de veículos e/ou apresentassem representatividade econômica, a exemplo das regiões Sul e Sudeste, que viabilizassem tais investimentos privados.

De acordo com Pereira (2007), para que as estradas federais saiam do estado de deterioração e possam contribuir para a aceleração do crescimento do País, são necessários R\$ 33 bilhões em investimentos nos próximos três anos, para expansão, restauração e conservação de importantes rodovias. Contudo, não há viabilidade financeira para que o governo federal realize esses investimentos, fato justificado pela liberalização, pela União, de $\mathrm{R} \$ 3,3$ bilhões para a conservação de estradas, duplicação de rodovias e expansão de ferrovias, no primeiro semestre de 2007 (RITTNER, 2007).

Além do aspecto financeiro, há que se considerar a questão ambiental que impera sobre a pavimentação da rodovia BR 163 no estado do Pará, a qual atravessa uma das regiões mais importantes da Amazônia em termos de diversidade biológica e riquezas naturais (CASA CIVIL, 2005). Sendo assim, não basta apenas apontar sobre a necessidade de se pavimentar e revitalizar a rodovia BR 163 Cuiabá-Santarém e a rodovia BR 364. Há que se avaliar também as questões ambientais e sociais envolvidas nesse processo.

Se pavimentada, a rodovia BR 163, no Pará, atrairá um contingente populacional e de investimentos produtivos que, se feitos de maneira desorganizada e sem planejamento, têm impactos ambientais negativos. Desse modo, a implantação de uma infraestrutura de transportes na região poderia proporcionar a penetração da agropecuária e do garimpo com pressões sobre os ecossistemas regionais, com desmatamento nos cerrados e na floresta tropical, por exemplo. Isso porque, conforme aponta a Casa Civil (2005), a maior parte das áreas não protegidas legalmente e que são constituídas por Unidades de Conservação e Terras Indígenas, especialmente no Pará e Amazonas, são terras públicas ou devolutas que se tornarão objetos de lutas, especulação e grilagem ${ }^{16}$.

Como forma de proporcionar um desenvolvimento sustentável da área de influência da rodovia BR 163, o Plano BR 163 Sustentável, relativo à pavimentação da rodovia no trecho Cuiabá-Santarém, incorpora uma série de avanços. Destaca-se a formulação de estratégias e ações para o desenvolvimento regional sustentável nos estados do Pará, Mato Grosso e Amazonas, retomando a concepção de políticas de desenvolvimento regional.

16 De acordo com a Casa Civil (2005), a grilagem frequentemente está associada a atos ilícitos, como o trabalho escravo e outras violações dos direitos humanos e trabalhistas, a evasão de impostos, a extração ilegal de madeira e a lavagem de dinheiro do narcotráfico. 
464 - A Precariedade do Transporte Rodoviário Brasileiro para o Escoamento da Produção de Soja do Centro-Oeste: situação e perspectivas

Esse plano busca impedir que a pavimentação do trecho da rodovia tenha impactos negativos ambientais na região. Um dos elementos mais importantes é a necessidade de se ampliar a presença do Estado em todas as suas instâncias, de forma a garantir maior governabilidade sobre os movimentos de ocupação e maior capacidade de orientação para os processos produtivos. Sendo previsível, portanto, que, a partir da conclusão da pavimentação da BR 163 e da restauração de seu trecho já pavimentado, haja uma intensificação dos fluxos migratórios para a região. O Plano BR -163 Sustentável apresenta uma estratégia de fomento às atividades produtivas, com base no ordenamento territorial, reconhecimento da diversidade sociocultural e uso do manejo florestal sustentável (CASA CIVIL, 2005).

Em resumo, o projeto de pavimentação da BR 163 constitui-se em uma obra estratégica para o desenvolvimento regional e nacional. Não será apenas um corredor de escoamento de grãos da região Centro-Oeste para o mercado internacional, mas, também, uma via de transporte da produção agrícola para os mercados do Centro-Sul e Nordeste do País. Ademais, esse projeto viabilizará o abastecimento de insumos às atividades produtivas e será uma alternativa para o escoamento da produção da Zona Franca de Manaus (CASA CIVIL, 2005).

No entanto, as estratégias priorizadas no Plano BR-163 Sustentável são ações meramente indicativas para os planos de governo. Atualmente, as rotas alternativas para o escoamento da produção de soja dos cerrados pelo Norte do País dependem da pavimentação dessa rodovia, cujos planos ainda não se concretizaram.

Portanto, o governo deve promover parcerias com o setor privado para inversões à revitalização da malha rodoviária brasileira, com destaque para as rodovias BR 163 e BR 364. No entanto, a iniciativa privada não tem interesse pelas rodovias das regiões mais longínquas do centro econômico do País. Assim, a Parceria Público Privada (PPP) pode ser um instrumento que, combinando satisfatoriamente rentabilidade, incerteza e riscos, seja eficiente na solução da escassez de investimentos para as rodovias não objetos de concessão, como é o caso da BR 163 e da BR 364.

Devido à dificuldade em despertar o interesse das concessionárias por rodovias em outras regiões, a solução das PPP é o que vai prevalecer nessas áreas, visto que a remuneração do parceiro privado dependerá não apenas da tarifa cobrada dos usuários. Em adicional, se prevê uma contraprestação do parceiro público de forma a viabilizar os investimentos privados.

Embora o instrumento da PPP para o asfaltamento do trecho da rodovia BR 163, ainda em leito natural, proporcione um salto de competitividade ao produto brasileiro, sendo uma solução ao seu estado precário de conservação, recentemente, essa rodovia foi retirada, pelo governo, da carteira de projeto da PPP, por motivos considerados técnicos, estando sua pavimentação inserida no Programa de Aceleração do Crescimento (PAC), como investimento público.

Assim, conforme apontado pelo Ministério da Integração Nacional (2006), a recuperação dos investimentos em infraestrutura de transportes na região 
Centro-Oeste depende da própria capacidade da poupança pública e dos incentivos aos investimentos privados, por meio das PPP, que são influenciados pelos ambientes microeconômicos e regulatório do País.

Conforme o Balanço PAC (2010), os investimentos em obras para a consolidação da BR 163 como rota de escoamento nacional já estão em andamento ou previstos no PAC. A pavimentação da rota Guarantã do Norte/MT-Santarém/ PA, incluindo o acesso a Miritituba BR-230/PA está prevista para ser concluída no quarto trimestre de 2011, com investimentos de R\$ 955 milhões até 2010 e de R\$ 460 milhões após esse ano. O projeto tem como executores o Departamento Nacional de Infraestrutura de Transportes (DNIT), Exército Brasileiro e a Prefeitura Municipal de Guarantã do Norte. O projeto de investimento nessa rodovia está dividido em três trechos, quais sejam:

- Trecho 1 (Rurópolis-Santarém): estão previstos $125 \mathrm{~km}$ de trechos de rodovias para pavimentação. Desse total, o trecho compreendido do km 914 ao km 893 foi entregue em 30/12/2008. A pavimentação do trecho do km 893 ao km 873 estava prevista para ser concluída até 30/12/2009, e o trecho do $\mathrm{km} 873$ ao $\mathrm{km} 789$ deve ser finalizado até 30/12/2011, sendo que o projeto executivo foi aprovado em 18/09/2009 e o início da obra estava previsto para 30/10/2009;

- Trecho 2 (Divisa MT/PA - Rurópolis e acesso à Mirituba (BR 230/PA $33 \mathrm{~km}$ ): estão previstos $822 \mathrm{~km}$ de rodovias para pavimentação. Desse total, o trecho de Rurópolis (entrada $\mathrm{km} \mathrm{230)} \mathrm{teve} \mathrm{as} \mathrm{obras} \mathrm{iniciadas}$ em 01/07/2009. Do trecho correspondente do km 230 ao km 355, foram concluídas as pontes dos rios Arraias e Itapacurazinho e estão em execução três pontes sobre os rios Itapacurá, Espinho e Parada. As obras nesse trecho tiveram o edital de licitação publicado em 21/08/2009. Entre o km 355 e o km 103, que correspondem a cinco lotes, as obras tiveram início em 19/08/2009. O trecho correspondente ao km 103 (divisa de Mato Grosso e Pará) teve o processo de licitação solicitado em 09/06/2008, com o projeto executivo sendo aprovado em 10/09/2009.

O projeto de pavimentação do trecho 2 da rodovia BR 163, que compreende a Divisa Mato Grosso/Pará - Rurópolis e o acesso à Mirituba, ainda apresenta muitas obras cujo término está previsto para 30/12/2009 e muitos projetos apresentam uma previsão de início das obras em até 30/01/2010. Contudo, o último Balanço do PAC disponibilizado é referente ao segundo quadrimestre de 2009, sem os resultados dessas previsões.

- Trecho 3 (Guarantã do Norte-Divisa MT/PA e travessia urbana de Guarantã): estão previstos $53 \mathrm{~km}$ de rodovias para pavimentação. O trecho que corresponde à divisa de Mato Grosso/Pará - Guarantã deve ser concluído em 30/08/2010. A finalização do trecho referente à travessia urbana estava prevista para 30/12/2009, mas as obras foram interrompidas pela empresa contratada, que solicitou revisão contratual. O trecho referente a essa 
466 - A Precariedade do Transporte Rodoviário Brasileiro para o Escoamento da Produção de Soja do Centro-Oeste: situação e perspectivas

travessia urbana tem a licitação renovada até 15/10/2009, e a previsão do DNIT quanto à manutenção do convênio ou a continuidade das obras pelo exército era de até 10/10/2009.

Como analisado pelo Balanço do PAC (2010), há, ainda, vários trechos da rodovia BR 163 no Norte do País com obras em execução ou, até mesmo, sem ter iniciado. São obras que demandam longo prazo para concretização e que exigem elevadas inversões de capital.

Ainda assim, no que tange ao componente regulatório, são identificadas ineficiências pelo lado do agente regulador. Quando há a sua captura pelos grupos de interesses, por exemplo, há um esvaziamento do órgão regulador com a perda de sua credibilidade e eficácia. No Brasil, o arcabouço institucional e os marcos regulatórios nem sempre produziram os resultados adequados, sendo esse ainda um desafio às políticas voltadas à privatização da infraestrutura.

De qualquer forma, existem estudos e projetos de caráter indicativo para subsidiar as ações dos próximos governos, tanto por meio de programas regionais territorialmente definidos como a partir de programas nacionais multimodais associados aos processos de desenvolvimento econômico e social do País - caso do Plano Estratégico de Desenvolvimento do Centro-Oeste (2007-2020) e do Plano Nacional de Logística de Transporte (PNLT).

Para a infraestrutura logística, o programa abrange a ampliação e recuperação do sistema de transportes, com vistas a aumentar a competitividade da economia da região, enfrentando os seus estrangulamentos de transporte de forma a integrá-la com o resto do País e com os países andinos. Nesse contexto, a integração multimodal deve abrir duas alternativas de escoamento da produção da região. A primeira visa à saída pelo porto de Santarém, com a revitalização logística da rodovia BR 163 e da capacidade de escoamento do porto, e a segunda refere-se à saída pelo porto de Itaqui (MA), combinando hidrovia com a ferrovia Norte-Sul e Carajás.

De acordo com o Ministério da Integração Nacional (2006), na análise de um cenário futuro ideal para o Centro-Oeste, o resultado de condições exógenas e endógenas é uma nova fase na história da região, que combinará crescimento econômico com melhorias nas condições de vida e redução relevante da degradação ambiental.

Nesse cenário, haveria uma melhoria nas condições de conservação e de tráfego das rodovias em $31,33 \%$ em 2010, contra os atuais $28,38 \%$. Em 2015, se prevêem melhorias em cerca de $40 \%$ das rodovias e, em 2020, em 58,76\%. Para isso, o estudo prevê investimentos na ordem de $\mathrm{R} \$ 4,95$ bilhões, ao ano, em rodovias e ferrovias.

No entanto, não se têm vislumbrado alternativas reais para solucionar a precariedade logística da região Centro-Oeste, e se estima a necessidade de investimentos anuais de US\$ 4,6 bilhões para recuperar a malha rodoviária de transportes brasileira - valor este equivalente ao montante necessário para 
combater o estrangulamento logístico apenas dos cerrados (MINISTÉRIO DA INTEGRAÇÃO NACIONAL, 2006).

Em resumo, os investimentos na logística do Centro-Oeste devem abranger recursos públicos, de baixo retorno financeiro de curto prazo, haja vista o papel estratégico do governo, além de ações por parte do setor privado, na concepção das concessões rodoviárias e das PPPs - instrumento que ainda precisa se fortalecer institucional e juridicamente.

No contexto do desmoronamento público para a condução das políticas setoriais no País é que emerge o PNLT, com o objetivo de retomar o processo de planejamento no setor de transportes, constituindo-se num plano de médio e longo prazos. Um dos fortes vieses desse processo é a efetiva alteração da matriz de transportes de cargas, com associação a um uso mais intensivo e adequado das modalidades ferroviária e aquaviária com base em suas eficiências energéticas e de produtividade no transporte de cargas de maior densidade a distâncias maiores. Busca-se, ainda, uma melhor integração multimodal com o sistema rodoviário, para o qual se propõe um concentrado esforço de restauração e manutenção, acompanhado de importantes obras de construção, pavimentação e ampliação da capacidade (PNLT, 2007).

Dos projetos com viés para o desenvolvimento socioeconômico do País, a região Centro-Oeste se insere no de Indução ao Desenvolvimento de Área de Expansão de Fronteira Agrícola e Mineral (IDF), que engloba a pavimentação ou construção de rodovias, além da implantação de novos eixos ferroviários que favorecem o escoamento da produção de grãos. Ademais, há projetos inseridos no Vetor Amazônico - que abrange grande área do Centro-Oeste -, recomendados como alternativas de escoamento da produção de soja dessa região.

Contudo, enquanto se vislumbram tais alternativas, o Centro-Oeste carece de amplos investimentos em transportes, permanecendo as deficiências das rodovias que o abastece. Ressalta-se a proliferação de vias informais ${ }^{17}$, sem nenhum controle do Estado, que, muitas vezes, intensificam a grilagem e o desmatamento, bem como criam condições para a disseminação do trabalho escravo, na medida em que possibilitam a abertura de fazendas em locais isolados (CASA CIVIL, 2005).

Embora muitas iniciativas estratégicas por parte dos próprios produtores estejam sendo comumente observadas nessa região como um instrumento eficaz no combate às ineficiências de transportes, as mesmas não devem ser interpretadas como a única solução a toda precariedade logística do País.

Em resumo, a produção de soja se expandiu de forma itinerante para o Centro-Oeste, tendo se deslocado com força, mais recentemente, para o Norte. Ocorre que, apesar da importância econômica dos cerrados brasileiros, essa região não apresenta condições logísticas eficientes para o escoamento da

17 De acordo com pesquisas do Instituto do Homem e Meio Ambiente da Amazônia (Imazon) apud Casa Civil (2005), estima-se que haja mais de 30 mil quilômetros de vias informais sobre a área de abrangência da rodovia BR 163 Cuiabá-Santarém. 
produção. No período inicial de expansão da oleaginosa, houve investimentos em rodovias e armazenamento, mas, ao longo dos anos, as vias ficaram sem conservação, restauração e ampliação. Atualmente, o cenário é de degradação e ineficiência, gerando perdas à competitividade do agronegócio brasileiro.

São várias as alternativas para solucionar o caos logístico no País. Contudo, quando se encontra solução para a escassez de recursos públicos, pelas concessões à iniciativa privada, por exemplo, enfrenta-se a falta de interesse da iniciativa privada, ou pela insuficiência econômica da região a ser atendida pelo investimento ou pela fragilidade regulatória do País.

Sendo assim, enquanto não se visualiza uma solução ou um projeto real para investimentos na infraestrutura de transportes, a produção brasileira de soja fica dependente de tapa-buracos para a "manutenção" da malha rodoviária e à espera da efetivação dos modais hidroviários e ferroviários, no contexto da intermodalidade, para a ampliação de sua competitividade internacional.

Ademais, empenhar-se em investimentos logísticos que permitam escoar a produção de soja pelos portos da região Norte sem considerar a capacidade dos portos é transferir o caos logístico que se concentra em épocas de safras nos portos de Santos e Paranaguá, para o Norte do País.

Portanto, infere-se ainda que, na emergência de uma política pública que repense sobre a matriz brasileira de transportes, de forma a substituir a função do modal rodoviário como principal meio de escoamento da produção para a função de ligação intermodal, estar-se-à reconhecendo a grandeza da riqueza do produto nacional. Destaca-se a competitiva produção de soja do CentroOeste que, além de depender de fundamentos macroeconômicos e regulatórios eficientes e estáveis, depende de uma infraestrutura logística moderna, eficiente e adequada à sua produtividade e às características territoriais do País.

\section{Conclusões}

Entre as principais conclusões deste trabalho está o fato de que a soja produzida na região Centro-Oeste do Brasil apresenta uma estrutura de transportes ineficiente para o seu escoamento. Por esse motivo, apesar de ter os menores custos de produção em relação aos principais produtores mundiais, ao chegar aos principais portos de exportação do País (porto de Santos e porto de Paranaguá), a oleaginosa se torna mais cara - a Tabela 3 mostra um comparativo das cadeias de soja do Brasil, Argentina e Estados Unidos.

Pela ineficiência do transporte da soja dessa região, concentrado no modal rodoviário, embora existam outras vias (hidrovia Tietê-Paraná, ferrovia Brasil Ferrovias, entre outras), o produtor brasileiro tem uma perda média de $25 \%$ em suas receitas com o custo de escoamento. Para um produtor norte-americano, essa despesa média é inferior a 10\% da receita obtida, o que permite concluir que é na circulação que a soja brasileira perde competitividade. 
O problema do escoamento da produção de soja pelo modal rodoviário é agravado pela deterioração das rodovias brasileiras. Destacam-se aquelas localizadas na região Centro-Oeste, em razão da crise financeira do Estado, que fez emergir um cenário de escassez de investimentos na grande área de fronteira agrícola e na infraestrutura de transportes do País.

Assim, as rodovias dessa região ficaram sem conservação e restauração, com muitas permanecendo em leito natural - casos de trechos da BR 163 e da BR 364. Resgatam-se, portanto, os dois tipos de custos logísticos relacionados ao modal rodoviário que inferem na competitividade internacional da soja brasileira. $\mathrm{O}$ primeiro relaciona-se à inadequação dessa modalidade às características do produto e às distâncias percorridas e, o segundo, à precária malha rodoviária brasileira por onde essa produção é escoada.

O fato é que, após 20 anos de consolidação da produção de soja no CentroOeste, não foi encontrada uma solução logística eficiente para o seu escoamento. A alternativa pelas concessões rodoviárias à iniciativa privada não reverte o estado precário das rodovias dessa região por estarem localizadas em uma área cuja baixa densidade econômica não resulta num elevado fluxo de veículos ao longo do ano que rentabilize os investimentos privados. Conclui-se, assim, que essas rodovias, principalmente trechos da BR 163 e da BR 364, dependem de investimentos puramente públicos para serem revitalizadas e, em razão da deterioração das finanças públicas, a alternativa pelas PPPs pode ser uma solução.

No que tange aos processos regulatórios aos processos de PPP, cabe à administração pública formular políticas e diretrizes, seja por meio de Ministério ou de conselhos interministeriais, enquanto às agências reguladoras cabe a implantação dessas políticas e diretrizes. Sendo assim, o ato regulatório deve, por objetivo, consubstanciar uma política pública setorial desenhada pelo governo.

Conclui-se, ainda, que a intermodalidade (com os transportes hidroviários e ferroviários) seria mais adequada para o escoamento da produção, devido à eficiência energética desses modais e à maior produtividade no transporte de cargas de maior densidade a maiores distâncias; em relação ao transporte rodoviário, confeririam custos entre $15 \%$ e $20 \%$ menores. No entanto, no País ainda persiste uma baixa oferta desses modais, dificultando o uso da intermodalidade para o escoamento.

Portanto, para que o transporte da produção de soja do Centro-Oeste tenha menores custos, é preciso que os segmentos envolvidos atuem de forma integrada e que se execute uma real política de transportes. São necessários projetos viáveis ao adequado escoamento, de forma a incentivar a intermodalidade, com a ampliação da oferta dos modais hidroviários e ferroviários, além de aumentar a capacidade dos portos e desenvolver a cabotagem no País, para que haja um transporte mais eficiente de commodities agrícolas e efetivas contribuições à economia brasileira. 
A Precariedade do Transporte Rodoviário Brasileiro para o Escoamento da Produção de Soja do Centro-Oeste: situação e perspectivas

\section{Referências Bibliográficas}

AFONSO, H. C. A. da G. Análise dos custos de transporte da soja brasileira. 2006. Tese de Mestrado (Engenharia de Transportes) - Instituto Militar de Engenharia, Rio de Janeiro. 138p.

ANCIÃES, A. W. da F. (coord.) et al. Avaliação Tecnológica do Álcool Etílico. Conselho Nacional de Desenvolvimento Científico e Tecnológico (CNPq). Coordenação de Avaliação de Tecnologias. 2º. Edição. Brasília, 1980. 514p

BAHIA, P. Q. et al. A competitividade da soja do Centro-Oeste através da logística de rede de transportes de grãos de soja para exportação do estado do Mato Grosso. In: XLV Congresso da Sociedade Brasileira de Economia, Administração e Sociologia Rural (SOBER), 45, Londrina, Paraná: Universidade Estadual de Londrina, 22 a 25 de jul. 2007.

BALANÇO PAC 2010. $2^{\circ}$ quadrimestre de 2009. Infra-Estrutura de Transportes. Disponível em: htpp.<www.brasil.gov.br/pac/balancos>. Acesso em: 10 jan. 2010.

BARTHOLOMEU, D. B. Quantificação dos impactos econômicos e ambientais decorrentes do estado de conservação das rodovias brasileiras. Tese de Doutorado (Economia Aplicada) - Escola Superior de Agricultura Luiz de Queiroz, Universidade de São Paulo, Piracicaba, 2006. 165f.

CAIXETA FILHO, J. V. (Org.) et al. Competitividade no agribusiness: a questão do transporte em um contexto logístico. Piracicaba, FEALQ, 1998. (Relatório técnico referente ao convênio FEALQ - Fundação de Estudos Agrários Luiz de Queiroz / FIA - Fundação Instituto de Administração, apoiado pelo IPEA - Instituto de Pesquisa Econômica Aplicada.

CAIXETA FILHO, J. V.; BARTHOLOMEU, D. B. Avaliação dos impactos da conservação das rodovias na emissão de gás carbônico pelo transporte rodoviário de cargas. In: Simpósio Internacional "O transporte e sua importância na cadeia produtiva global: políticas, ações para exportação", 2, 2002, Piracicaba UNIMEP, 2002.

CASA CIVIL. Plano de Desenvolvimento Regional Sustentável para a Área de Influência da Rodovia BR - 163 Cuiabá - Santarém. $2^{\text {a }}$ Etapa de Consulta à Sociedade, Março de 2005, 142 páginas.

CNT. Confederação Nacional dos Transportes. Transportes de cargas no Brasil. Centro de Estudos em Logística-COPPEAD, 2002. Disponível em: htpp. <www. cnt.org.br>. Acesso em: 04 Jan de 2006.

COELI, C. C. de M. Análise da demanda por transporte ferroviário: o caso do transporte de grãos e farelo de soja na Ferronorte. Tese de Mestrado (Administração) - Instituto COPPEAD de Administração, Universidade Federal do Rio de Janeiro (UFRJ), Rio de Janeiro, 2004. 136f. 
CONAB. Corredor de Escoamento da Produção Agrícola. Corredor da BR 163, 2007. Disponível em: http://www.conab.gov.br/conabweb/download/nupin/ Corredor_Escoamento\%20BR163.pdf>. Acesso em 10 set. 2007.

FLEURY, F. A infra-estrutura e os desafios logísticos das exportações brasileiras. Centro de Estudos em Logísticas (CEL), Instituto COPPEAD de Administração, Universidade Federal do Rio de Janeiro (UFRJ), 2005.

HIJJAR, M. F. Logística, soja e comércio internacional. Centro de Estudo em Logística. COPPEAD, UFRJ, Rio de Janeiro, 2004. Disponível em: <http://www. centrodelogistica.com.br/new/fs-public.htm > . Acesso em: 10 fev. 2007.

IBRE. Logística, o calcanhar - de- Aquiles do agronegócio. Conjuntura Econômica, Fundação Getúlio Vargas, Vol. 59, noo . 05, Maio de 2005.

JANK, M. S.; NASSAR, A. M.; TACHINARDI, M. H.. Agronegócio e Comércio Exterior Brasileiro. Revista USP, São Paulo, n. 64, p. 14-27, dez/fev. 2004/05.

LOPES, M. de R.; OLIVEIRA, M. S. de. Do apagão logístico à agroindustrialização. Conjuntura Econômica, Fundação Getúlio Vargas, Vol. 59, noํ. 05, Maio de 2005.

MINISTÉRIODAINTEGRAÇÃONACIONAL.PlanoEstratégicodeDesenvolvimento do Centro-Oeste (2007-2020), [2006?]. 224p. Disponível em: <http://www.integracao. gov.br/desenvolvimentodocentrooeste/index.asp?area $=\mathrm{SCO} \% 20-\% 20$ Publicações $>$. Acesso em 11 de set. 2007.

MINISTÉRIO DOS TRANSPORTES. Mapas e Informações. Disponível em: <http://www.transportes.gov.br/>. Acesso em: Jan. de 2007.

NATAL, J. L. A. Transporte, ocupação do espaço e desenvolvimento capitalista no Brasil: história e perspectivas. Tese de Doutorado (Economia), Universidade Estadual de Campinas (Unicamp), Campinas-SP, 1991. 256f.

PEREIRA, R. Recuperação de rodovias exige investimento de $\mathrm{R} \$ 33$ bilhões. $O$ Estado de São Paulo, 14 jan. 2007. Caderno Economia, p. B1

PNLT. PLANO NACIONAL DE LOGÍSTICA E TRANSPORTES. Sumario Executivo. Ministério dos Transportes e Ministério da Defesa. Abril 2007, 64 p.

REZENDE, G. C. de. Do Cruzado ao Collor: Os Planos de Estabilização e a Agricultura. Revista de Economia Política, vol. 12, no. 02 (46), Abril-Junho/1992.

RITTNER, D. Investimento em transporte atinge R\$ 3,3 bi no semestre. Valor Econômico, São Paulo, 4 de jul. 2007.

ROESSING, A. C.; TELLES, T. S.; GUIMARÃES, M. de F. Perfil da infra-estrutura de transportes para o escoamento da soja no Brasil. In: XLV Congresso da Sociedade Brasileira de Economia, Administração e Sociologia Rural (SOBER), 45, Londrina, Paraná: Universidade Estadual de Londrina, 22 a 25 de jul. 2007. 
472 - A Precariedade do Transporte Rodoviário Brasileiro para o Escoamento da Produção de Soja do Centro-Oeste: situação e perspectivas

ROESSING, A. C.; LAZZAROTTO, J. J. A cultura da soja no Brasil: evolução recente. EMBRAPA: Londrina, dez. 200

SILVA, R. B. da. Os caminhos da soja. Conjuntura Econômica, Fundação Getúlio Vargas, Vol. 59, no. . 05, Maio de 2005.

TAVARES, C. E. C. Fatores críticos à competitividade da soja no Paraná e no Mato Grosso. CONAB. 2004. Disponível em: < http://www.conab.gov.br/download/ cas/especiais/Trabalho\%20sobre\%20Competitividade $\% 20$ Soja $\% 20 \mathrm{MT} \% 20 \mathrm{e} \% 20$ PR.pdf. Acesso em 15 mar. 2007.

TIMOSSI, A. J. Grandes mudanças no escoamento de grãos. FNP Consultoria \& Agroinformativos. p. 427-478. 2003.

TORRES, C. L. O Intermodal a passos largos. Valor Setorial Ferrovias, São Paulo, p. 8-10, set. 2006. 